\title{
AmazonMath: um jogo educativo voltado para alfabetização matemática
}

\author{
Fernanda Gabriela de Sousa Pires ${ }^{1}$, João da Silva Queroga ${ }^{1}$, Karolayne Batista \\ Teixeira ${ }^{1}$, José Carlos da Silva Duarte Filho'
}

\author{
Laboratório de Tecnologias Educacionais (LabTEd) \\ ${ }^{1}$ Universidade do Estado do Amazonas (UEA) - Escola Superior de Tecnologia (EST)
} 69050-020 - Manaus - AM- Brasil

$\{$ kbt.lic, jcsdf.inf, jdsq.lic, fpires \}uea.edu.br

\begin{abstract}
Resumo. Este artigo trata do desenvolvimento de um aplicativo para a alfabetização matemática. O processo seguiu as linhas de desenvolvimento ágil e contou com a aplicação de testes com o público algo, crianças em processo de alfabetização, para validação do jogo. O software AmazonMath tem como objetivo principal o desenvolvimento da aprendizagem numérica, de forma dinâmica e divertida, levando o usuário a criar relações entre as quantidades e suas representações simbólicas. O cenário é a floresta, e os signos utilizados são amazônicos, visando uma aprendizagem significativa.
\end{abstract}

\section{Cenário de uso}

Os avanços da Ciência e da tecnologia modificaram a vida dos homens, em todos os setores, saúde, economia, entre outros. A Educação, por seu papel na sociedade, não pode ficar distante dessas modificações, os novos tempos, pedem novas ferramentas para aprendizagem (Schmidt, Resnick, \& Ito, 2016) .

Os jogos, fazem parte da formação social dos homens desde que sem informações, atualmente, vem sendo considerados alternativas lúdicas a serem utilizadas no processo de aprendizagem(Garneli, Giannakos, \& Chorianopoulos, 2017; Lim, 2017). Huizinga (2014) afirma que os jogos fazem parte da trama da vida, e sempre foram usados em processos de formação social, mas para ser efetivo eles precisam estar integrados a situações que levem ao exercício da análise e da reflexão (BRASIL \& Fundamental, 1997).

Assim, os jogos digitais são defendidos como uma boa alternativa no universo de aprendizagem escolar (Neto \& da Fonseca, 2013). Os jogos permitem que a jornada de aprendizagem seja prazerosa, gerando bons momentos que tendem a criar aprendizagem significativa e consequentemente, aumentem o engajamento na resolução dos problemas apresentados.

O jogo aqui proposto, denominado "AmazonMath", tem como objetivo promover a Alfabetização Matemática por meio de experiências lúdicas em que o usuário interage com o personagem e executa as missões que lhe são propostas, via áudio, ou seja, a criança não precisa saber ler para que possa interagir com o jogo. $\mathrm{O}$ jogo foi desenvolvido tendo como pressuposto teórico a Teoria Cognitiva da Aprendizagem Multimídia (Mayer, 2009) que pressupõe a existência de um canal duplo de processamento da informação e com isso se aprende mais através de palavras e 
VII Congresso Brasileiro de Informática na Educação (CBIE 2018)

Anais dos Workshops do VII Congresso Brasileiro de Informática na Educação (WCBIE 2018)

imagens do que somente com palavras ou imagens e a Teoria de Aprendizagem significativa, defendida por Ausubel (Ausubel, Novak, \& Hanesian, 1976) que postula que ao longo da vida, os serem humanos criam pontos de ancoragem com as informações capturadas ao seu redor estas são chamadas subsunsores, assim ao receber uma nova informação, esta é atrelada a uma memória já existente, criando assim uma rede de significados. O jogo é originalmente destinado a crianças, com faixa etária de 57 anos, que estão na primeira infância e no processo de aprendizagem inicial dos fundamentos matemáticos.

\subsection{Possibilidades de modelos de negócio}

O jogo oferece uma forma segura de interação com espaços relacionados com a cultura da Amazônia. Boa iniciativa de conservação ambiental e estimula o jogador a aprender como contar através do cotidiano.

A aplicação é de fundo educacional, tendo como objetivo proporcionar ferramenta de alfabetização matemática. Está sendo finalizada para publicação na PlayStore. Considerando que o aplicativo pode ser utilizado dentro e fora da sala de aula, com auxílio ou não do professor, o jogo pode ser aplicado como um objeto de aprendizagem para revisão e fixação de conteúdo, assim como pode ser jogado apenas para fins de diversão e entretenimento.

\section{Desenvolvimento}

O software AmazonMath foi desenvolvido na engine de jogos Unity, versão 2017, na linguagem C\#, no sistema operacional Windows 10. Foi desenvolvido para plataforma Android com exigência mínima de Target SDK para Android 5.0 - lançado a partir de 2014 - com exigência também de, no mínimo, 1,5 Gb de memória RAM.

O processo de desenvolvimento do aplicativo foi definido em quatro momentos distintos e sequencias. Com exceção do primeiro momento, os outros foram compostos por prototipação e validação. Prototipação é uma técnica que objetiva apresentar as funcionalidades, parte do designer e conceitos do produto em planejamento, antes do desenvolvimento do produto final. Validação são técnicas e métodos para a verificação da especificação dos requisitos, para assegurar se o aplicativo cumpre as funções das quais é designado e para a identificação de defeitos.

\subsection{Momento 1: Ideação, Levantamento de requisitos}

Ideação: Momento de concepção do Jogo, a equipe trabalhou usando técnicas de brainstorns para discutir as ideias e os temas propostos. Foram idealizadas as funcionalidades e as mecânicas, assim como algumas regras.

Levantamento de requisitos: Os requisitos levantados foram os seguintes:

R-1: Permitir que os usuários possam utilizar seus conhecimentos prévios de conhecer frutas e reconhecer o ambiente da floresta amazônica; 
VII Congresso Brasileiro de Informática na Educação (CBIE 2018)

Anais dos Workshops do VII Congresso Brasileiro de Informática na Educação (WCBIE 2018)

R-2: Permitir que o usuário possa utilizar o software mesmo sem a companhia de um adulto, pois o software possui narração, permitindo uma interação com o jogo;

R-3: Permitir que o usuário possa escolher qualquer nível para jogar, deixando o ambiente mais dinâmico;

R-4: Seguir um alinhamento didático no qual o tema, Floresta Amazônica, é abordado em todos os níveis, de acordo com os PCNs.

R-5: Oferecer um conteúdo dinâmico, tendo vários Puzzles, fazendo com que os usuários tenham vários desafios;

\subsection{Momento 2:}

Minimum Viable Product (MVP): Foi utilizada a ferramenta de apresentação multimídia Power Point nesta etapa. Validação dos Requisitos: o MVP foi construído de forma a apresentar a mecânica e os requisitos, portanto a validação dos requisitos aconteceu para verificar a presença e consistência dos requisitos no produto.

\subsection{Momento 3:}

Protótipo de Média Fidelidade: após as alterações e melhorias do momento anterior, o aplicativo começou a ser desenvolvido na engine Unity. Esta etapa consistiu na representação das funcionalidades e mecânicas de forma mais eficiente e real. Para isso foram criadas diversas versões para uso.

Experiência do Usuário: foi realizada uma apresentação do protótipo de médio nível para o público alvo, foi analisada a reação do usuário com o protótipo, de forma visual, para alterações que foram realizadas de acordo com resultados obtidos pelo teste, observando a estética, a usabilidade, a arquitetura de informação, o fluxo de interação e enfim a reação com o conteúdo.

\subsection{Momento 4:}

Protótipo de Alta Fidelidade: etapa de representação mais fiel do jogo. Momento de construção do produto final.

Avaliações de IHC: Os testes realizados foram do tipo Percurso Cognitivo, Usabilidade de Nielsen, Requisitos Educacionais, Heurística, TCAM, teste GameFlow e um relatório específico de percurso cognitivo. Os professores responderam o de Percurso cognitivo, TCAM e Gameflow, sendo observado a heurística. Universitários responderam sobre a usabilidade e observação da heurística e os Discentes (usuários do público alvo) responderam apenas os de requisitos educacionais e algumas perguntas quanto à satisfação do uso.

\section{Apresentação do Software}

\subsection{Conceito do Jogo}

AmazonMath é um jogo de aventura e quebra cabeça, em terceira pessoa, que coloca a Arara Tito em situações de aprendizagem Matemática, contando as frutinhas da Amazônia, para poder se manter vivo. Auxiliando na compreensão da importância das 
VII Congresso Brasileiro de Informática na Educação (CBIE 2018)

Anais dos Workshops do VII Congresso Brasileiro de Informática na Educação (WCBIE 2018)

frutas para a manutenção da vida na floresta Amazônica. Aprender a contar, ordenar e somar pode auxiliar o Tito nessa jornada.

O usuário deve realizar atividades de acordo com que o personagem Tito instruir. Os momentos de instrução são ambientados com sons e ruídos referentes a uma floresta tropical.

\subsection{Mecânicas do gameplay}

O jogador ajuda a Arara Tito a contar e relacionar a quantidade numeral com objetos. A cada nível existem pequenas fases, cada fase possui um tempo para realizar e vale uma estrela. O jogador precisa possuir, no mínimo, 10 estrelas para poder se manter alimentado. Algumas mecânicas pedem que se insira frutas na cesta, ordenar os números nos troncos de madeira e conectar peças de quebra-cabeça. O usuário irá receber uma estrela por cada atividade realizada, durante o tempo estipulado; a cada 10 estrelas haverá uma recompensa maior.

O jogo é dividido em seis níveis e cada nível possui em média 10 fases. O usuário irá responder e interagir com o personagem Tito e com elementos do ambiente para desenvolver habilidade de contar frutas e ordenar de forma crescente os números, entre outras atividades tudo realizado por meio da telado touch screen.

\subsection{Descrição das Telas}

O ambiente é a floresta Amazônica; haverá um background estático.

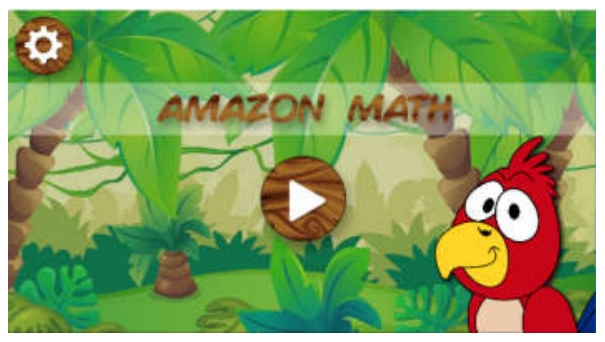

Figura 1. Tela inicial na versão final

Tela inicial: O usuário tem acesso às configurações e iniciar o jogo, sendo direcionado para a escolha de Níveis.

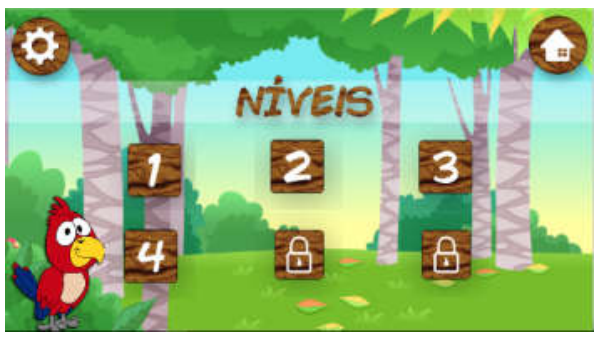

Figura 2.Tela de níveis

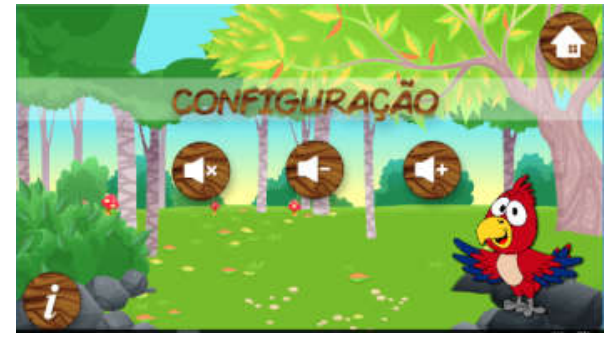

Figura 3. Tela de Configuração

Tela de Níveis: permite acesso aos quatros níveis e as opções de configuração ou voltar para tela inicial. 


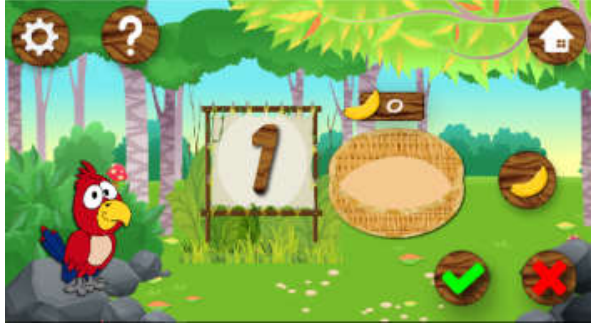

Figura 4.Tela de Nível 1 Fase 1

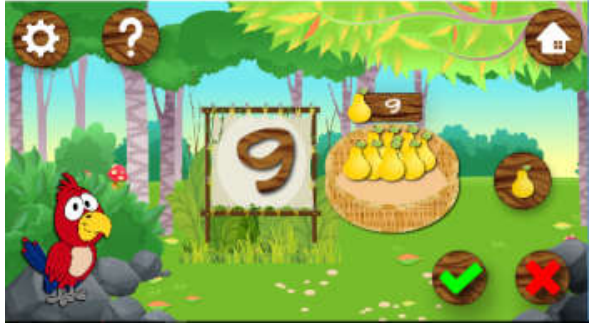

Figura 5. Tela de Nível 1 Fase 9

Nível 1: O usuário tem acesso a 10 fases no nível 1, o usuário deve colocar na cesta a quantidade de frutas que o Tito pede, são no total de 10 sessões nesse nível, com frutas diferentes. O botão de "?" possui a descrição da fase. Após clicar no botão aparece o desafio da fase, além disso, o usuário pode retornar para tela de menu quando desejar.

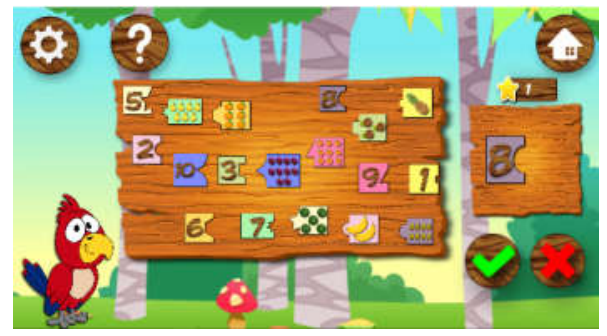

Figura 5. Tela de Nível 2

Nível 2: O usuário tem que encontrar as peças que se encaixam. O objetivo na aprendizagem é conseguir identificar a relação entre quantidade e o número.

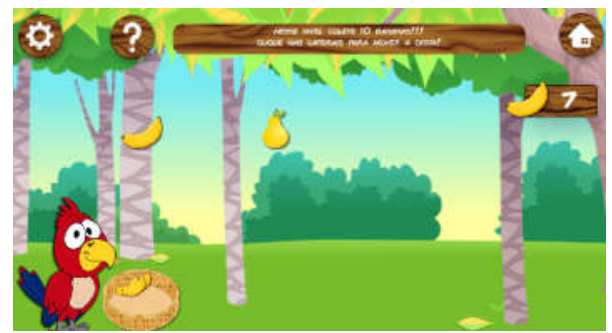

Figura 6. Tela de Nível 3

Nível 3: O objetivo é coletar 10 bananas de forma regressiva, ou seja, aprender os fundamentos da subtração pois o contador de bananas inicia com 10 .

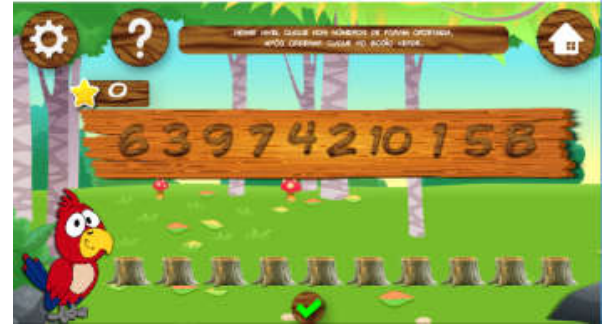

Figura 7. Tela de Nível 4, inicio do nivel

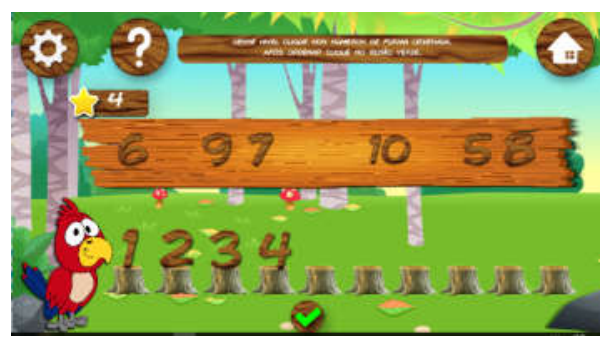

Figura 8. Telas de Nível 4 com ordenação de quatros números 
VII Congresso Brasileiro de Informática na Educação (CBIE 2018)

Anais dos Workshops do VII Congresso Brasileiro de Informática na Educação (WCBIE 2018) 
VII Congresso Brasileiro de Informática na Educação (CBIE 2018)

Anais dos Workshops do VII Congresso Brasileiro de Informática na Educação (WCBIE 2018)

Nível 4: O objetivo do nível é ordenar os números nos troncos. O objetivo é conseguir identificar de forma ordenada as posições dos números.

\section{Trabalhos Futuros}

O objetivo futuro seria incrementar o game para adicionar novas fases que cubram mais sessões no processo de alfabetização Matemática.

O jogo atualmente possui algumas metas a cumprir; Após os testes é possível implementar correções para o alcance das metas, visando melhoria nos seguintes quesitos:

Q-1: Configuração do áudio e efeitos sonoros;

Q-2: Melhores Feedbacks;

Q-3: Otimização do funcionamento;

Q-4: aprimorar os níveis existentes com relação à gamificação;

Q-5: Permitir a conexão com redes sociais para comparar pontuação;

Q-6: desenvolvimento de melhores Power-ups e devidas premiações;

Q-7: melhor interatividade com o personagem;

\section{Considerações finais}

As métricas adotadas, para a análise dos testes, foram avaliadas com notas de 0 a 5 (0 Não existe nenhum elemento; 1- Existem alguns elementos; 2- Suficiente; 3- Bom; 4Ótimo; 5- Perfeito.).

De acordo com a realização dos testes, o software foi bem aceito no quesito educacional design (observações sobre a tabela de cores do nível 4). Nos demais quesitos as notas variaram de 4 a 5, tendo como média geral 4.57. A avaliação dos professores entrevistados apresentou média geral de 3.60 e o quesito com maior rejeição, segundo os mesmos, é a falta de recursos relacionados a um feedback de tentativa e erro, o qual possibilitaria uma melhor visualização do desempenho do usuário.

Dos 10 discentes entrevistados, apenas 1 atribuiu nota 3 para o jogo. O mesmo preferia jogos com cenas de violência, porém relatou que gostou do nível 2. Foi pedido que os discentes escolhessem um nível de maior preferência pessoal e as escolhas foram, respectivamente: 4 para o nível 2; 3 para o nível 3; 2 para o nível 1; e 1 para o nível 4 . As crianças demonstraram grande interesse em usar a ferramenta, com o pedido insistente a favor do uso contínuo.

\section{Referências}

Ausubel, D., Novak, J., \& Hanesian, H. (1976). Psicología cognitiva. Un punto de vista cognoscitivo. Mexico: Trillas.

BRASIL, \& Fundamental, d. d. E. S. d. E. (1997). Parâmetros curriculares nacionais: matemática: MEC/SEF Brasília.

Garneli, V., Giannakos, M., \& Chorianopoulos, K. (2017). Serious games as a malleable learning medium: The effects of narrative, gameplay, and making on students' performance and attitudes. British Journal of Educational Technology, $48(3), 842-859$. 
Huizinga, J. (2014). Homo ludens: o jogo como elemento da cultura. Estudos. São Paulo: Editora da Universidade de S. Paulo: Editora Perspectiva.

Lim, H. (2017). Computational Thinking (CT) and Rebel game Design: CT in health games. Paper presented at the Serious Games and Applications for Health (SeGAH), 2017 IEEE 5th International Conference on.

Mayer, R. E. (2009). Multimedia Learning: Cambridge University Press.

Neto, J. F. B., \& da Fonseca, F. d. S. (2013). Jogos educativos em dispositivos móveis como auxílio ao ensino da matemática. RENOTE, 11(1).

Schmidt, J. P., Resnick, M., \& Ito, J. (2016). Creative learning and the future of work. Disrupting Unemployment, 147-155. 